LA-UR- 92-958

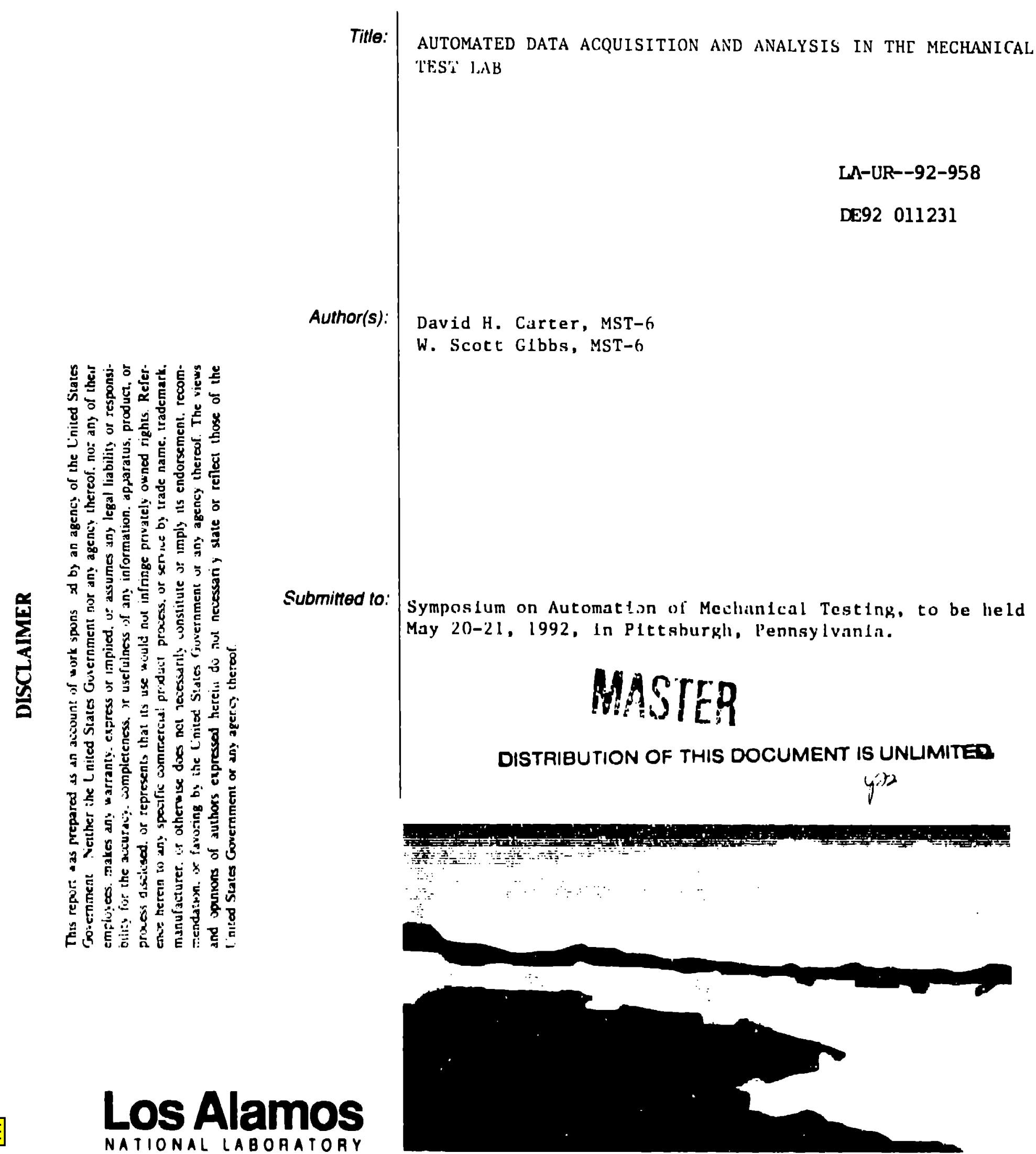

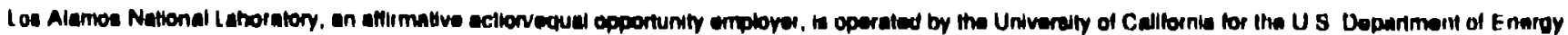

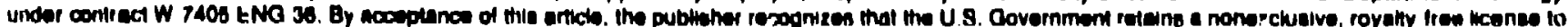

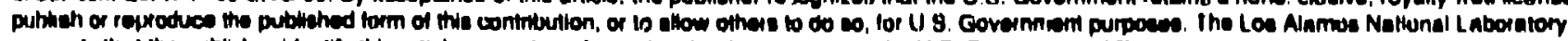

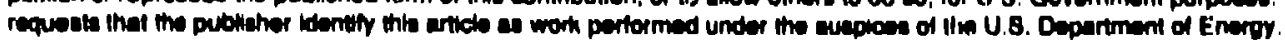




\title{
Automated Data Acquisition and Analysis in the Mechanical Test Lab
}

\author{
David H. Carter \\ W. Scott Gibbs \\ Los Alamos National Laboratory \\ Los Alamos, NM 87545 USA
}

\begin{abstract}
Computers and enhanced control technoiogy have made it possible to p.rform more sophisticated mechanical tests than ever before, as well as to allow routine tests to be run and analyzed with much greater efficiency. Automated data acquisition, storage and analysis have become key ingredients in a mechanical test facility, especially in one which utilizes a wide variety of test equipment and techniques. 'This paper will discuss one such mechanical test facility where many different ty; 'mechanical tests are performed utilizing automated data acquisiti in, centralized data st orage and finally a complex system of autom ted data analysis. Various systems of data acquisition will be discuss 3d, including those used on servohydraulic and screwdriven systems, as well as those used for higher-rate, formability and creep tests. Methods for networking equipment used in such a. facility will be described. Networking is an important criterion for establishing a centralized data base, and for eventually building a system of automated data anaiysis.
\end{abstract}




\section{Introduction}

The charter of this mechanical test lab is to provide the highest possible quality mechanical characterization facilities for advanced materials development programs within the Los Alamos National Laboratory. Some of the advanced materials studied in these programs may require characterization at extreme environmental conditions, such as elevated and cryogenic temperatures.

This paper will focus on some of the unique features of this lab related to automated data acquisition, networking, and data analysis. These are three key ingredients which have made this lab a high quality, efficient mechanical test facility.

The first section will describe varions pieces of equipment in this lab, and in particular, the data acquisition system related to each machine. In the next section, the network as a whole will be described. Finally, the data analysis system will be outlined.

\section{Automated data acquisition systems}

This mechanical testing lab provides mechanical characterization services on metals, ceramics, plastics and composites at temperatures ranging from 4 to $3273^{\circ} \mathrm{K}$. Typical strain rates are on the order of $10^{-8}$ per second to 5 per second.

These operations include but are not limited to tensile, compression, bend, impact, and fracture toughness testing of and on a wide variety of metals, ceramics and plastics. These tests are performed over a wide variety of environmental conditions that include gascous atmospheres, vacuum, acidic and basic liquids as well as metal salts and liquid metals. Some test methods are performed to applicable AS'IM standards. Other material characterization requirements may diciate that non standard, unique, test methods must be employed.

Some of the pieces of test equipment utilized are a Gleeble 1500/20, two Instrons, an M'I'S 88055 kip test system, an M'TS 886 metal forming system, crexp testing machines, both constant atress and constant load, an impression creep test system, a charpy impact tester, an M'TS drop tower, an M'TS 142 600 kip test system, a fractometer, a fracture toughiness tester, an "M'T'Stron", which is an Inst,ron servo-hydraulic load frame with an M'TS controller 
and a vacuum chamber, and an MTS 810 test system.

Key features which make a data acquisition system successful in a large networked environment such as this are the abilities to:

- provide high accuracy and reliability,

- be capable of high speed data acquisition,

- utilize standard format for data to facilitate networking and efficient analysis,

- provide data in a convenient form for use by the researcher to perform additional specialized analysis,

- and to provide direct digital data input for numerical modelling of materials and structıres.

For the test equipment in this iab, each of the above features have been addressed.

\section{$2.1 \quad$ MTS 88055 kip servo-hydraulic load frame}

The MTS 88055,000 pound system bas the grentest overall capability in the section. Tensile, compression, fraciure mechanics, fatigue, and flexure testing is done on this system with applied loads ranging from a few pounds to 50,000 pounds. Some materials commonly tested are U.W, Be, and W-NiFe. This system is equipped with dual servo valves. For most tests the 1 and $10 \mathrm{gprn}$ valves are itistalled. For higher frequency or faster rate testing the 1 zpm servo valve may be replaced with a $10 \mathrm{gpm}$ valve. In this configuration, with dual $10 \mathrm{gpm}$ valves, the actuator is capable of traveling 240 inches per minute. Normal compact tension sampies can be tested at 60liz. Wiih the $1 \mathrm{gpm}$ valve in place the maximum ram speed is 12 inches per minute.

This machine can be used for elevated temperature testing, using a quartz lamp furnace capable of $1200^{\circ} \mathrm{C}$. In addition, a $10 \mathrm{KW} \mathrm{RF}$ induction heating unit and a resistance furnace are available for use on this load frame.

Up to 8 channels of strain gages may be recorded using the instrumerta tion attached to this had frame. Data acquisition and test aystem control is performed through a DE(: Micro.PI)P' 11/23, interfaced to an M'TS 148 series controller and function generator. 
Much of the specialized test software used in controlling tests is supplied by MTS. For most tests, however, a simple function generator routine is used, and the data is acquired by software written in-house. This software, which is separate from the data acquisition software, is written to acquire the raw data and to store it using a standard format. By writing our own data acquisition software for each piece of equipment, the data file format can be standardized so that it can be easily read by the data analysis software, which will be described later. Scme of the commercial software has been modified to provide the standard data file output.

\subsection{Two Instron screw-driven load frames, 10 and 20 kip}

Two Instron screw-driven machines, with capacities of 10,000 and 20,000 pounds are used for tensile, compression and flexure tests. The rosshead on these frames have a minimum speed of 0.0002 inches per minute and a maximum speed of 20 inches per minute.

The 20,000 pound load frame has a cryostat for low temperature tensile and compression testing to $4^{\circ} \mathrm{K} . \Lambda$ variety of inaterials are tested cryogenically, including $\mathrm{Be}, \mathrm{Cu}$, and $\mathrm{Al}$. The 10,000 pound frame is used for tensile and compression tests at ambient test conditions. An environmeatal charnber can also be installed on this frame. The temperature range on this chanber is -70 to $1315^{\circ} \mathrm{C}$.

The two screw driven Instron load frames are operated by one controller in the lab. Data is acquired by commercial software on an IBM personal computer through an HP-IB interface to the Instron controller. This computer is on the network, as are all of the computers in this lab. In this manner, the data can be stored directly onto the main file server.

\subsection{MTS 810600 kip servo-hydraulic load frame}

'This loart frame is designed primarily for compression tosing. loads applied to the sample can range from a few pounds to 600,000 pounds, based on the size of the sample being tested. Testing is performed at ambient conditions. 


\subsection{Charpy impact tester and MTS drop tower}

A standard instrumented Charpy impact machine capable of providing 300 ft.lbs of impact energy to the sample is used for testing to the ASTM E23 standards. In addition, several novel tests have been developed to measure coating spall behavior using this impact tester.

The MTS drop weight tower can deliver $4000 \mathrm{ft}$.lbs of impact energy to the sample. This device uses a guided drop hammer to fracture the sample.

Impact testing is performed using standard ASTM techniques. The drop tower has had an instrumented tup added. Data is collected from both the Charpy impact machine and the drop tower using a high-speed data acquisition board in an IBM personal computer which is networked. This data can be plotted as absorbed energy as a function of time.

\subsection{Four creep frames}

Creep tests are used to determine low strain rate, high temperature material properties. Two constant stress, one constant load, and one impression creep frame are used to perform creep tests at elevated iemperatures. This involves loading the sample essentially with dead-weights, and recording the behavior of the material over long periods of time, normaily hundreds of hours.

Modifications to the extensometers have been made so that dual high precision LW'T transducers can be mounted on each specimen. This allows for bending moments in the linkages to be averaged out of the strain signal that is recorded by the computer. Current sensitivity allows displacements of $1 \mu \mathrm{m}$ to be measured casily. 'Thia resolution corresponds to strains of $0.01 \%$ in the current buttonhead specinen.

Data acquisition is performed by an IBM personal computer, which can monitor and acquire data from all four frames simultancously. The computer is interfaced to a data logger through an HP.lB interface. Creep dala is stored directly onto the main file server. Because of this, one can monitor the progress of a creep test using the data analysis of tware from a computer in any office, or even by logging into a workstation from home via a modem. This is especially useful for creep tests, which normally have long durations. 


\section{6 "MTS-tron" 20 kip servo-hydraulic 4 post load frame}

This is a 20,000 pound Instron 4 post load frame controlled by an MTS 458 series controller and micro-profiler. It is equipped with a cryo-pumped vacuum chamber with a $100 \mathrm{KW}$ RF induction heating power supply, directly coupled to the hot zone of the rams. The rams are 2.75 inch diameter stainless steel, with alumina insulation between the stainless steel and the hot zone, which is normally made from TZM. The design allows for replaceable plattens which can be made from different materials, depending on the test temperature.

The system is used primarily for hot deformation studies on materials and for diffusion bonding. The micro-profier can be programmed for any type of test, including a constant true strain rate tensile ur compression test. The controller and micro-profiler are connected to an iBM personal computer using an MTS interface card.

\subsection{MTS 81022 kip servo-hydraulic load frarne}

This load frame is configured primarily for fracture mechanics and fatigue testing. The dual $10 \mathrm{gpm}$ servo valves described for the 880 system above are installed on this frame. However, due to the smaller actuator, the inaximum travel speed of the actuator is 300 inches per minute with no load or $60 \mathrm{~Hz}$ operation with a 10,000 pound load through a 0.01 inch strcks. This load frame is also configured to accept the cryostat from the 20,000 pound Iristron load frame.

\subsection{MTS Cup-forming and formability testing ma- chine}

This unique machine is used to evaluate the formability of sheet materials using a hydraulic bulge test. 'This system is also noed to fabricate sinall sheet metal components to very tight tolerances. 


\subsection{Gleeble $1500 / 20$}

Samples of various configurations are tested under tension or compression in the Gleeble. The samples are enclosed in a vacuum controlled atmosphere chamber during testing. The testing cycle typically consists of subjecting the eample to a programmed thermal cycle (achieved by passing a controlled electrical current through the specimen) and simultaneously deforming the specimen in tension or compression. The sample is held in or between interchangeable water cooled jaws.

The load frame is capable of applying $20000 \mathrm{lbs}$ force to the sample with crosshead speeds of 2800 inches per minute. Heating rates to $105^{\circ} \mathrm{C}$ per second are possible with the direct resistance heating employed on this system. The maximum controlied temperature of the system is $3273^{\circ} \mathrm{K}$.

The Gleeble is interfaced with a Compaq personal computer for both control and data acquisition. This computer is on the network, and so data can be stored directly on the main file server.

\section{Mechanical testing systems network}

A DEC Microvax II has been utilized to form the foundation of a network which consısts of mechanical testing equipment, personal computers, workstations, and many different peripherals. This network allows researchers to access both mechanical test data and data anaiysis software from their own personal computer or workstation. The network started out as a small thinwire ethernet system, connecting only the mechanical test lab and the Microvax II, as well as a couple of personal computers. It has quickly grown to a large network of over 30 personal computers and workstations, a central file server, and a varicty of printers and output devices. It now spans our entire facility, including labs and offices in almost every section of our group. The network is also connected to the rest of the world via Internet. 'This allows us to transfer data and reports to customers and collaborators in any part of the world, which has proven to be very useful in a number of ongoing programs. The computing power has been substantially upgraded with the addition of a number of DECstations, which are very fast RISC-based workstations. 'These are used for data analysis, as well as various modelling activities which previously required Cray super-computers. A diagram of the 
network is shown in Figure 1. Since the network is constantly growing, this figure is only a partial representation.

MST-6 Network

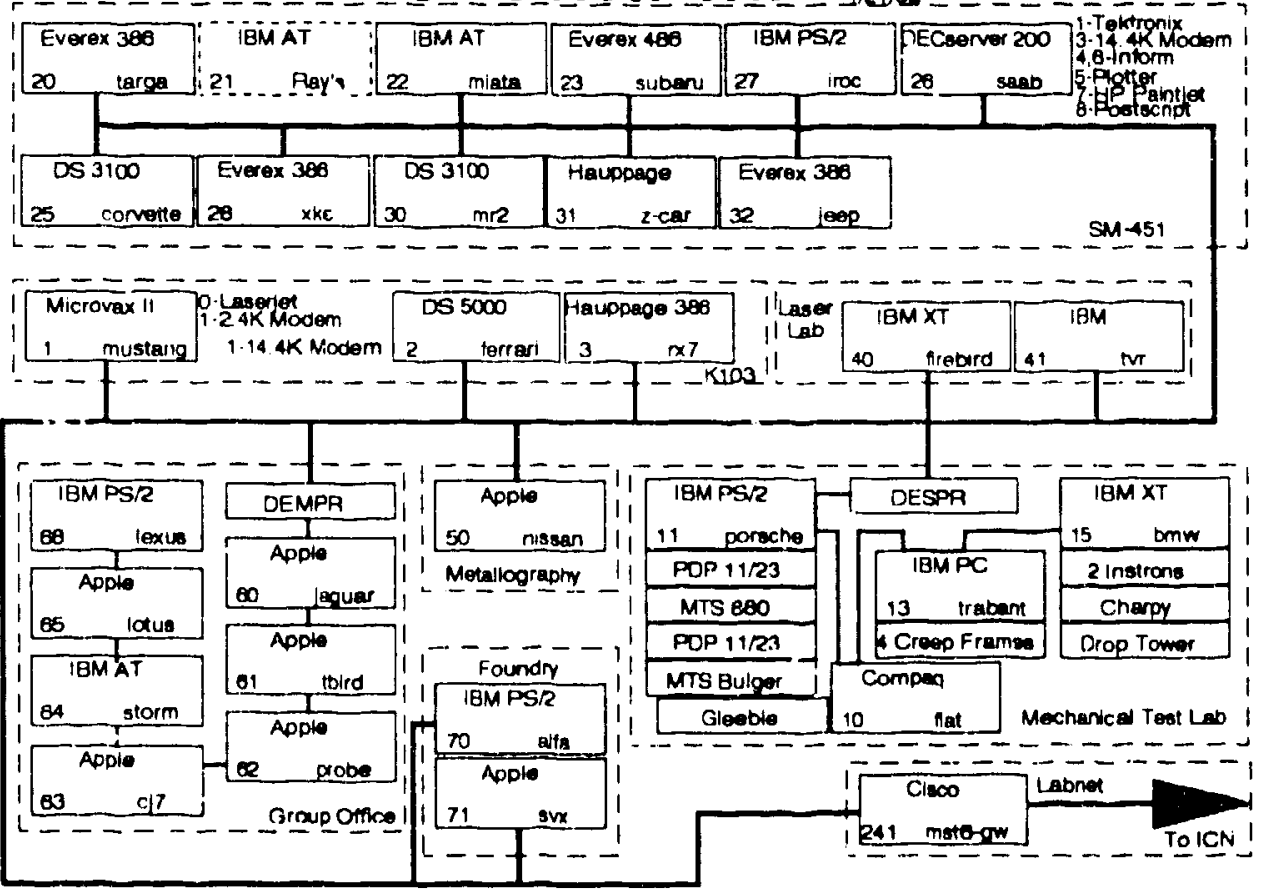

Figure 1: Network configuration diagrarn

The widest line on this diagram represents the backbone ethernet, which spans the entire building. There are a number of computers in the mechanical test lab interfaced to the various pieces of mechanical test equipment, some of which is shown in this figure. In other areas of the building, personal computers in most offices are networked. The Cisco is the local network's interface to the Internet, which is cur link with the rest of the world. The computers are represented by boxes, each having its own Internet name and address. The computers are named after cars.

All of the data collected on the various mechanical test machines (as well as data collected in other labe in the building) is stored on the central file server, named Mustang, which has a current capacity of approximately 3 gigabytes. This can be accessed by any of the computers on the network. 
Figure 2 is a graphical representation of this concept, showing how the various data is collected and stored on the central file server, for access by the rest of the network.

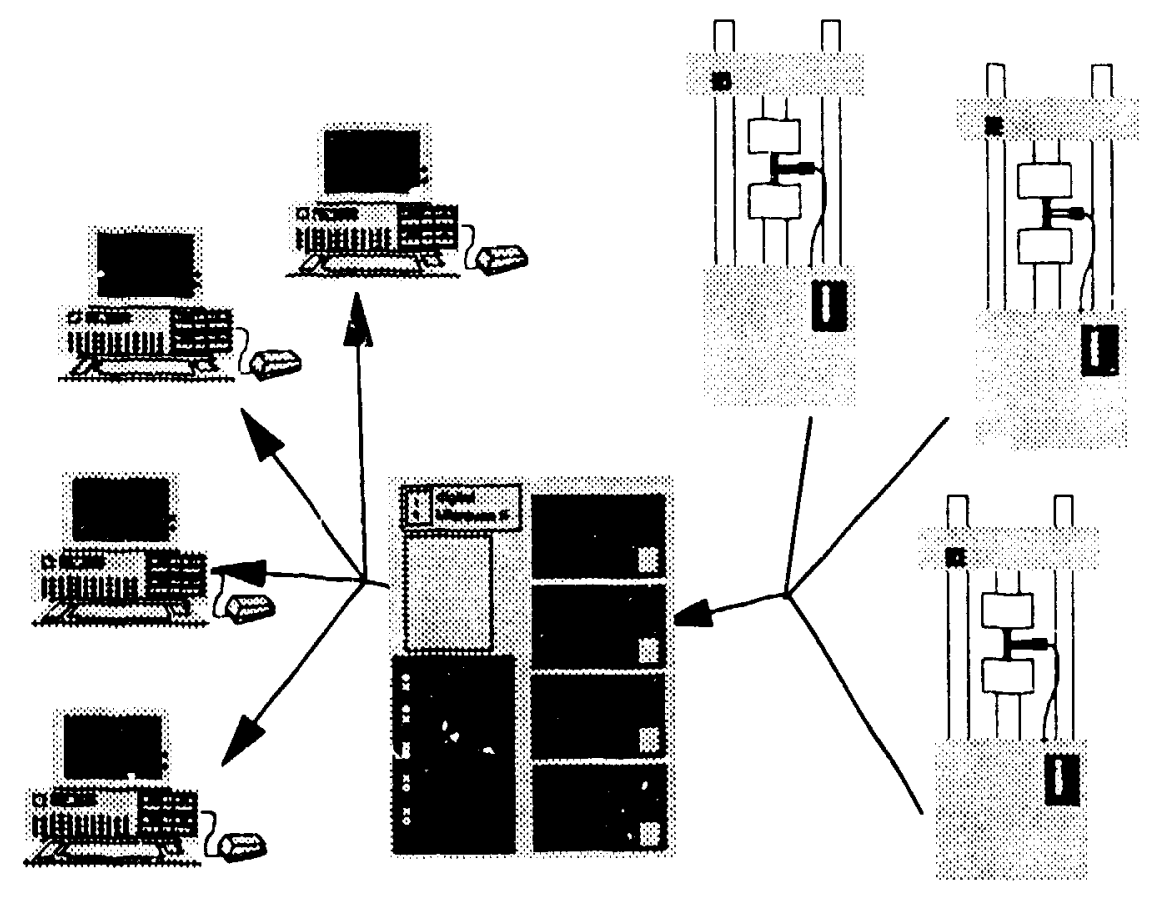

Figure 2: Data from tests stored on central file server for access by personal computers and workstations

One method of access is through the data analysis system, which will be outlined in the following section. Data can also be accessed directly by any of the workstations or personal computers. For example, one could pefform a specialized analysis, by loading the data into a spreadsheet. This sharing of data and software is represented grapinically in Figure 3.

The network has been very successful so far. Members of the group in all sections of the building have utilized both its vast file storage capabilities and the computing power of the DECstations. The network allows the transfer of large data files quickly and easily from one machine to another. It also allows information such as data and reports to be shared easily annong researchers, both within the group and outside the lab. 


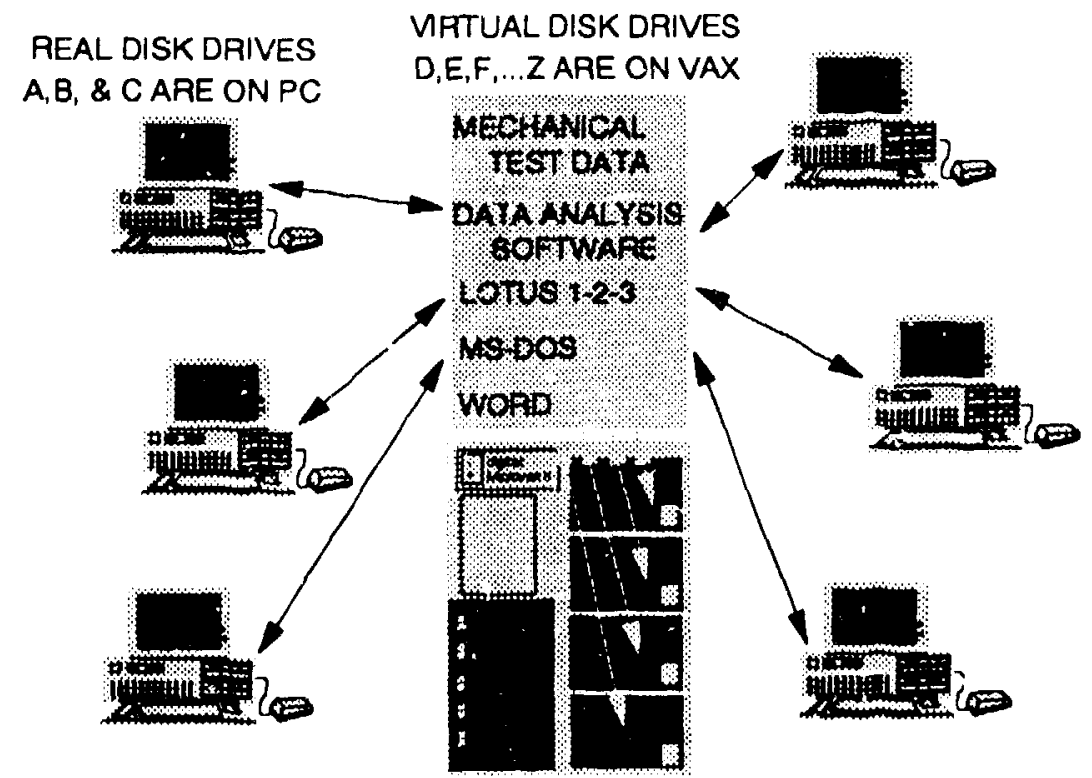

Figure 3: Personal computers and workstations share data and software via the central file server

\section{Data analysis software package}

The data anaiysis software package allows data to be analyzed in a very efficient, accurate mancer. It is flexible enough to analyze many different types of tests, and, because of its modular structure, is easily changed to analyze data using any test techniques that may be developed in the future. The software is extremely user-friendly, so that anyone may analyze their own data, whether or not they have ever used a computer. This way, the researcher requesting the test has the opportunity to analyze their own results if they wish, since they sometimes know best what they are looking for in the data.

The software is easily accessible throughout the building by any of the personal computers or workstations on the network. The program uses two libraries of graphical routines called CGS and CGSHIGH which were developed at Los Alaros National Lab. The analysis software runs on the 
DECstations, so any computer with the appropriate graphics terminal emulation software may access it. Currently, the user interface uses Tektronix graphics calls, and so every computer uses a Tektronix 4105 emulator to run the software. There are plans to include an $\mathrm{X}$ windows user interface as well. Most user input can be provided with a mouse pointing device or arrow keys.

In this section, a sequence of steps performed to analyze a simple data file from a tensile test will be described. It is assumed that the user has logged in using the mechanical test analysis account password, which starts the program automatically. In screen 1 below, the initial screen prompts the user to input the type of test they would like to analyze; a stress-strain or creep test. In this and all further cases, the user makes their selection by pointing with the mouse and clicking, or moving the cursor with the arrow keys and hitting space. The creep analysis routines, which will not be described here, have very similar options to the stress-strain analysis routines. However, under the creep menu there are some additional analysis routines such as "theta-projection" programs, which use sophisticated curve fitting formulas.

After the user selects the type of test to analyze, screen 2 prompts the user for a directory in which to find the file they would like to choose. These directories are normally organized by project, or sometimes by material. Screen 3 prompts for the file name within the chosen directory.

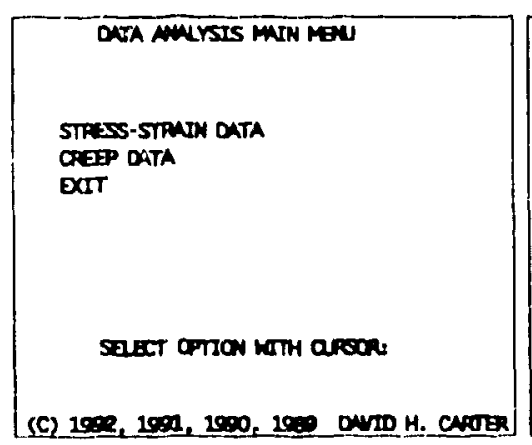

Screen 1

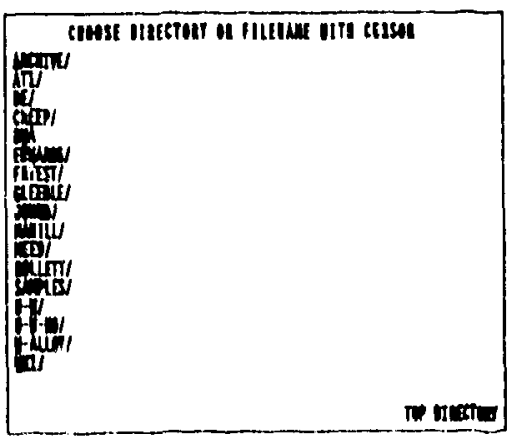

Screen 2

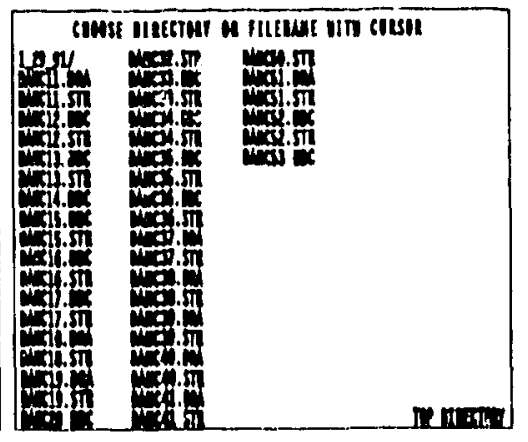

Screen 3

Once the user hay selected the data file to reduce, the nrogram reads the file, and interprets the data. The data acquisition sc ware on each of the various mechanical test equipment places some important "header" information at the beginning of each raw data file. The header describes 
the type of test being run, the rame of the test, and some other crucial information, such as test sample dimensions. The first line of this header relays to the data analysis program how many header lines there are, how to interpret the information found in the rest of the header, how many columns of raw data to look for in the file, and what each criumn represents. By storing the data in this fashion, the user of the data analysis software need not know any information about the data file, how it was taken, or even which machine was used to acquire the data, since the data analysis software can interpret this information from the data file.

Screen 4 shows the main menu for analyzing data from a stress-strain curve. Before analyzing the data, it is sometimes required to edit the stressstrain data file. This is because there is sometimes erroneous data in the file after the test is over, for example. There can also be electronic "glitches" which cause erroneous data points. Rather than editing the data by hand, or by importing it into a spreadsheet, this program allows the data to be edited graphically. The next few screens show the sequence of steps involved in one such edit operation. By clicking on "edit stress-strain data file", screen 5 prompts for a variety of edit operations. This particular data file appears normal, except for some extra data after the test was over. By clicking on "set min and max for curve" in screen 5 the stress-strain curve can be easily cleaned up. Screen 6 prompts for the minimum ard screen 7 prompts for the maximum real data point. Note that in all of these operations, the program will choose the point closest to the cursor location-the user does not have to click on the precise location of the point.

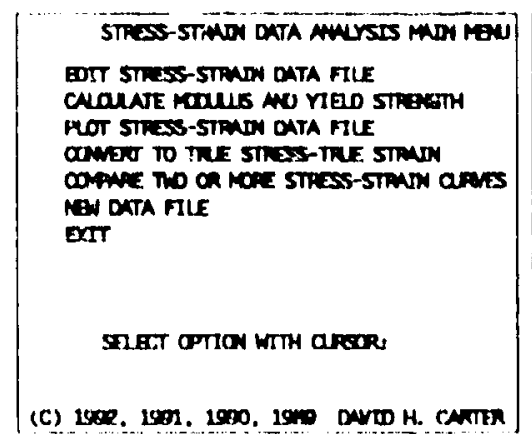

Screen 1

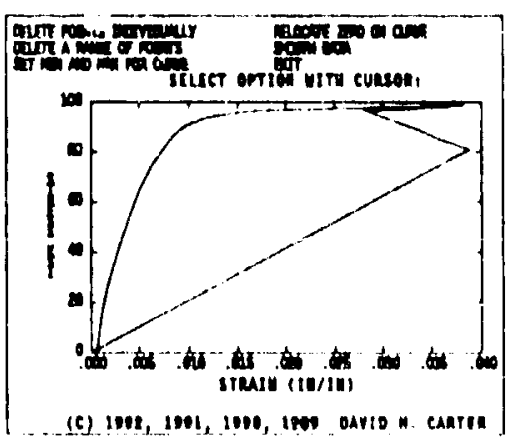

Screen 5

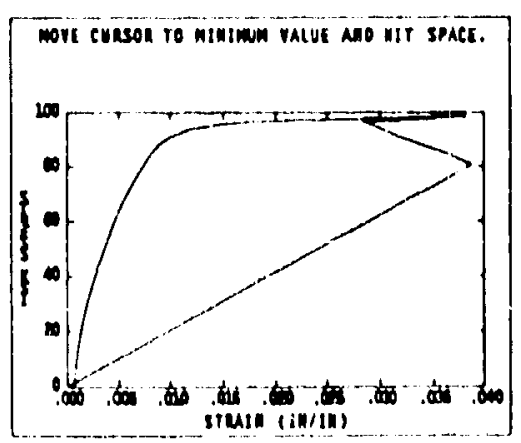

Screen 6

Scresil 8 assures that the program has fiosen the correct data points by marking them with red asteriaks and prompting the user to make sure that 


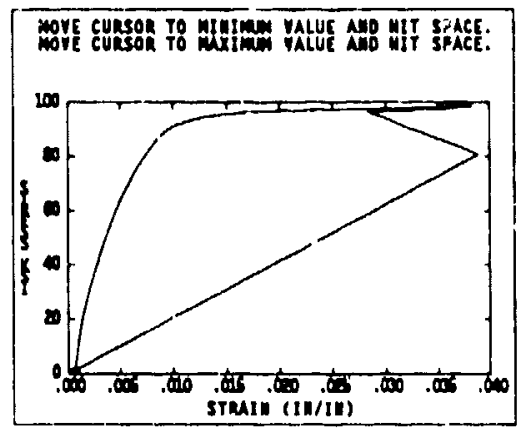

Screen 7

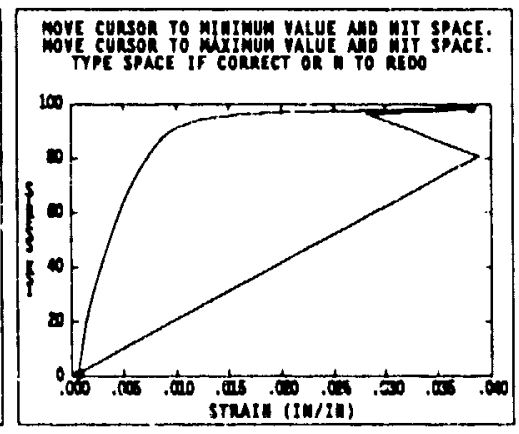

Screen 8

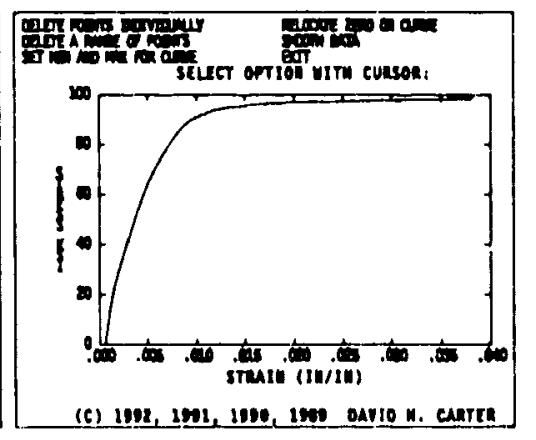

Screen 9

this is really what they want to do. The user is also given the option to redo this operaticn. Screen 9 brings the user back to the edit menu, and displays the edited data file. At this point, the user may continue editing, or return to the main menu. If the user chooses to exit, the program asks if the data file should be stored in a "standard" format. This saves the edited data, so that the edits do not have to be repeated every time the file is analyzed. It also stores the data as stress-strain data, so that the raw load-displacement data doee not have to be reduced again.

Now that the data has been edited, the program brings the user back to Screen 10. The next few screens show the steps involved to calculate elastic modulus and yield strongth. We have found that the best way to calculate modulus is through a graphical approach. There are many computer programs available to calculate modulus using a variety of numerical approaches. The modulus calculated by this program, however, is done purcly based on the user choosing the correct limits between which the program calculates a linear fit to the data. We have found that this approach normally provides just as accurate results an most of the numerical approaches.

In screens 11 and 12 , the user is prompted for the miaimum and maxirrum data points between which to calculate the modulus. The program marks these choices with red asterisks, and in screen 13, plots the caiculated modulus. The mininum and maximum values chosen in this example are marked with asterisks in screen 13. 'The program also prints the value of the calculated modulus at the top of the screen. The user can choose to repeat this operation as many times as needed, to assure that the calculated value is accurate. If it is, the program then asks if a yicld strength should be calculated. 'The user is given a choice as to the offset to uae in this calculation 


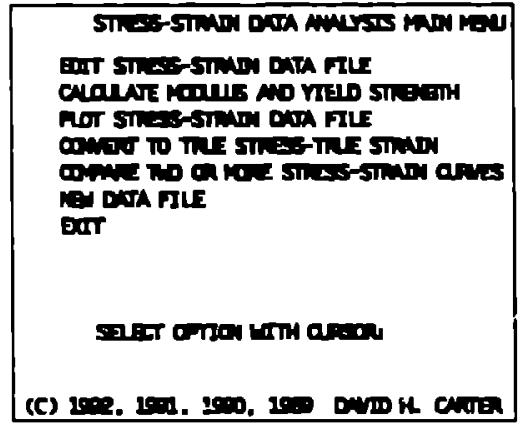

Screen 10

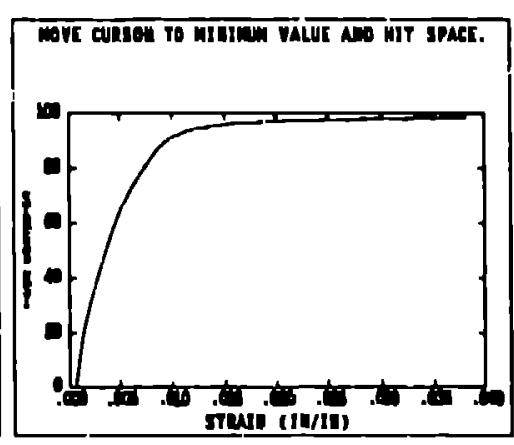

Screen 11

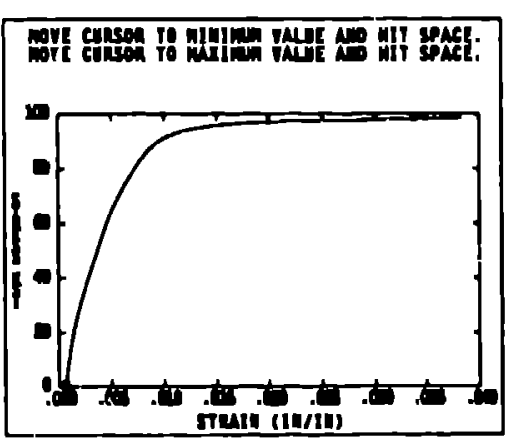

Screen 12

(normally $0.2 \%$ ). In screen 14 , the strcss-strain curve is replctted, showing the modulus and yield strength lines, and the calculated values of the elastic modulus, yield strength, and ultimate strength, as well as the test name, at the top of the screen. 'I'he user is given an opportunity to output this to a pen plotter or otber graphics output device, and then returned to screen 15 .

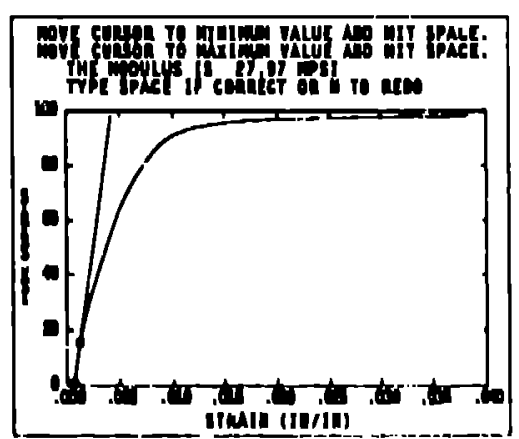

Screen 13

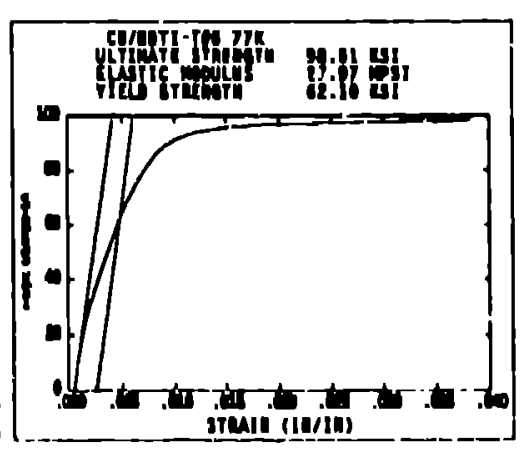

Screen 14

The third option on screen 15 allows the uscr to simply plot the stress. strain curve without the modulus and yield strength lines, as in screen 16. If the morlulus and yield sirength has been calculated through option 2, the program will provide those values at the top of the sereen.

The remainiug menu options shown in screen 15 will not be discussed here, as they are fairly aclf-explanatory. The creep data analysis main menu is fairly similar to the stress-strain data analysis main menu shown in acrecn 15. The creep portion of the progrum does include some additional curve fitting routinen, which use theta projection annlysis techniques. This in one 


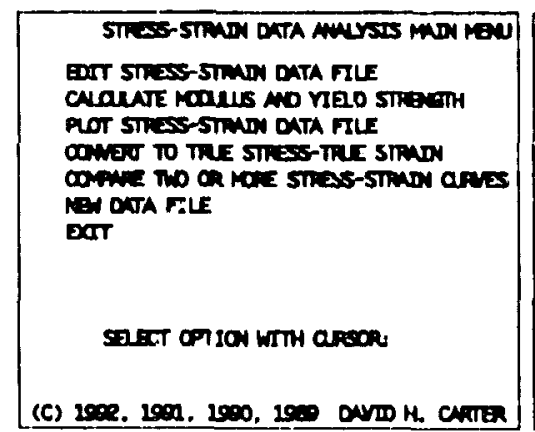

Screen 15

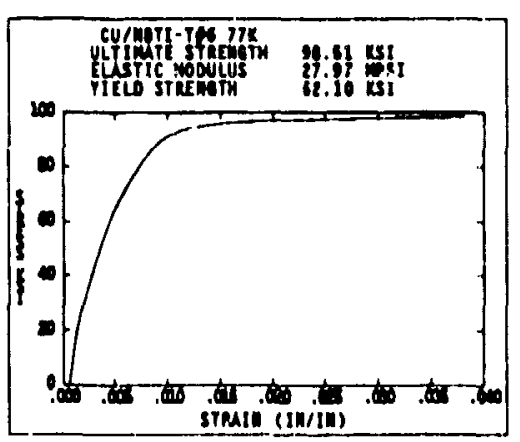

Screen 16

method which can be used by the researcher to predict lo \& term creep behavior from relatively short term creep experiments.

\section{Concluding remarks}

This laboratory has quickly grown from a few pieces of test equipment and a couple personal computers to a large network connecting many machines, computers, and other devices. This progress has proved extremcly valuable in maintaining efficient operations. One exrmple of the usefulness of this network is a ccrtain progi am which is a collaborative effort with an industrial partner on the opposite side of the country. 'The resenrcher involved is able to analyze the data from thrir tests while sitting in their ofince. They can then write a report incorporating this data, und e-mail the $\mathrm{r}^{-}$, country. In this manner, the partner on the opposite side of the country can have instant access to not juat an "executive summary" of their resulls, but to the actual raw data from their mechanical teata.

It has been shown how this particular laboralory has integrated automated data acquiaition, networking, and data analyais into an extremely eflicient, high quality mechanica' tent facility. Although this laboratory may differ from others in the delaila of ita setwork configuration nnd analyais noft. ware, it is very important to addrean these three kay actors when planning such a laboratory, enpecinlly a far!bity which utilizes a wide variety of tent mujument and techmiques. 